\title{
Fermented milk products: effects of lactose hydrolysis and fermentation conditions on the rheological properties
}

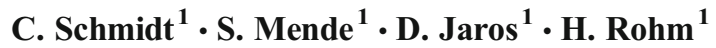

Received: 2 July 2015 / Accepted: 3 September 2015 /

Published online: 2 October 2015

C) INRA and Springer-Verlag France 2015

\begin{abstract}
Lactose-free dairy products become increasingly important for lactoseintolerant consumers, but there are only few studies concerning the rheological properties of fermented dairy products from lactose-hydrolysed milk. Hydrolysation was performed with commercial $\beta$-galactosidase either before or during fermentation (cohydrolysis). In each trial, fermentation of the base milk was carried out simultaneously using the same starter cultures for (a) untreated milk (reference) (b) hydrolysed milk as substrate and (c) by performing lactose hydrolysis and fermentation simultaneously (co-hydrolysis). In total, five thermophilic starter cultures and two products (yoghurt and Greek-style yoghurt) were investigated. Results show that the influence of hydrolysis of lactose on the properties of the fermented dairy products strongly depends on starter culture and substrate. For starters C and D, apparent viscosity (extracted from flow curves at a shear rate of $75 \mathrm{~s}^{-1}$ ) of fermented milks was only marginally affected by lactose hydrolysis, ranging between approx. 0.34-0.31 and 0.37-0.31 Pa.s, respectively. Hydrolysed products from starters A and E exhibited significant lower apparent viscosity ( 0.16 and 0.24 Pa.s) compared with their respective references $(0.29$ and 0.35 Pa.s). Fermentation of both substrates (regular yoghurt, Greek-style yoghurt) with starter B resulted in a decrease of yield stress and apparent viscosity because of lactose hydrolysis only for Greek-style yoghurt. Furthermore, a trend towards higher EPS synthesis was found when using hydrolysed milk. The results clearly show that products made from lactose-hydrolysed milk with similar rheological properties as the reference product can be obtained but that there is a lack of information concerning the complex interactions between starter culture and milk substrate.
\end{abstract}

Keywords Yoghurt $\cdot$ Lactose hydrolysis $\cdot$ Rheological properties

D. Jaros

doris.jaros@tu-dresden.de

1 Chair of Food Engineering, Technische Universität Dresden, 01062 Dresden, Germany 


\section{Introduction}

Lactose intolerance comes from the insufficient resorption of lactose in the small intestine, caused by a reduced activity or the absence of $\beta$-galactosidase. Consequently, undigested lactose reaches the colon where it is fermented by the colon microbiota into e.g. methane, hydrogen and lactate which cause symptoms such as flatulence, abdominal pain and diarrhoea (Mlichová and Rosenberg 2006; Schaafsma 2008). Because of these negative effects, lactose-intolerant consumers avoid the intake of milk and lactose-containing foods. Sales opportunities of lactose-free products are high all over the world, especially in countries with a high percentage of lactoseintolerant people (Harju et al. 2012; Jelen and Tossavainen 2003). More than $70 \%$ of the world population suffers from lactose intolerance (Vasiljevic and Jelen 2003), but its occurrence largely depends on the population group: only approx. $10 \%$ of Northern Europeans but more than $90 \%$ of South-East Asians suffer from this intolerance (Jelen and Tossavainen 2003).

$\beta$-D-Galactopyranosyl-( $(\rightarrow 4)$-D-glucose (= lactose) is the main carbohydrate in milk (Schaafsma 2008). Hydrolysis by $\beta$-galactosidase, which can be isolated from, e.g. plants, animals, yeasts, fungi and bacteria (Harju et al. 2012; Husain 2010; Mlichová and Rosenberg 2006), is one of the most important biotechnological processes in the food industry. $\beta$-Galactosidases from Kluyveromyces lactis, Kluyveromyces fragilis, Aspergillus niger and Aspergillus oryzae are most commonly applied because they are available in high amounts and low-priced compared to lactase of animal or herbal origin (Husain 2010; Mlichová and Rosenberg 2006).

Not only lactose hydrolysis serves for producing milk products that are tolerated by lactose-intolerant people, but also hydrolysed products taste sweeter because of the higher sweetness of the individual monosaccharides (Adhikari et al. 2010; Harju et al. 2012; Novalin et al. 2005). Consequently, in yoghurt from hydrolysed milk, the amount of added sugar can be reduced, resulting in a product with lower energy (Mlichová and Rosenberg 2006). For the manufacture of lactose-free base milk, mainly free enzymes are used. Some lactases, however, exhibit proteolytic activities that may cause a bitter after taste (Harju et al. 2012; Nagaraj et al. 2009).

Only a few studies refer to the influence of lactose hydrolysis on the characteristics of fermented milk. Some studies reported on a reduction of fermentation time in case of hydrolysed base milk (Matijević et al. 2011; Nagaraj et al. 2009), whereas others (Ibarra et al. 2012; Toba et al. 1986) observed an increase of fermentation time or rather no effects. Consequently, a strong influence of the starter culture must be assumed. Hydrolysis of lactose can also be performed simultaneously with fermentation. This so called co-hydrolysis is usually preferred, because it saves extra processing time for hydrolysis and omits additional energy costs (Günther 1983). Concerning fermented products, Vènica et al. (2013) did not detect differences in syneresis and sensory properties between drinkable yoghurt from not hydrolysed and co-hydrolysed milk, whereas in sensory tests of Toba et al. (1986), co-hydrolysed yoghurt was rated as unacceptable because of its strong sweetness and the occurrence of an off-flavour. Ibarra et al. (2012) found that the sensory quality of yoghurt declined with increasing lactose hydrolysis degree, and Nagaraj et al. (2009) detected increased syneresis of yoghurt from hydrolysed milk. Yoghurt from milk with 50 and $70 \%$ of lactose hydrolysed before 
fermentation exhibited a creamier texture and a better flavour than yoghurt from nothydrolysed milk, whereas $90 \%$ lactose hydrolysis resulted in products with lower viscosity and a too sweet flavour. Martins et al. (2012) hydrolysed more than $97 \%$ of lactose during fermentation with 0.5 and 1.0 g. $\mathrm{L}^{-1}$ lactase. The products that contained less enzyme exhibited higher viscosity and lower syneresis despite a similar degree of hydrolysis. The authors speculated that this can be explained by a lower amount of exopolysaccharides (EPS) synthesised in case of higher enzyme concentration; however, EPS concentration was not determined.

The aim of our study was to investigate the influence of different strategies of lactose hydrolysis and the contribution of the starter cultures on viscosity and texture of regular yoghurt and Greek-style yoghurt. For a systematic approach, fermentations of not hydrolysed milk (reference), of milk that was hydrolysed before fermentation and of co-hydrolysed milk (addition of $\beta$-galactosidase and starter concomitantly) were performed simultaneously for each starter culture.

\section{Materials and methods}

\subsection{Production of the base milk}

For the production of regular yoghurt (further encoded as 12), reconstituted skim milk was prepared by dissolving low-heat skim milk powder (SMP) (Sachsenmilch Leppersdorf GmbH, Leppersdorf, Germany) in deionised water at a concentration of $120 \mathrm{~g} . \mathrm{kg}^{-1}$ and by subsequent stirring at $300 \mathrm{rpm}$ with a three-wing propeller mixer $\left(d=70 \mathrm{~mm}\right.$ ) for $30-45 \mathrm{~min}$ (final base milk $116 \mathrm{~g} . \mathrm{kg}^{-1}$ dry matter, $38.7 \mathrm{~g} . \mathrm{kg}^{-1}$ protein, ratio casein/whey protein $=4: 1$ ). The substrate for Greek-style yoghurt (further encoded as 14) was reconstituted skim milk (100 g.kg $\left.{ }^{-1}\right)$, enriched by $40 \mathrm{~g} \cdot \mathrm{kg}^{-1}$ Promilk $852 \mathrm{~A}$ milk protein isolate (IDI SAS, Arras Cedex, France) with a casein/whey protein ratio of 11.5:1. The final base milk for Greek-style yoghurt had $135 \mathrm{~g} . \mathrm{kg}^{-1}$ dry matter, 64 g. $\mathrm{kg}^{-1}$ protein and a ratio casein/whey protein of $6: 1$.

For each fermentation trial, $3.5 \mathrm{~kg}$ base milk was produced. After storage at $4{ }^{\circ} \mathrm{C}$ for at least $24 \mathrm{~h}$, the milk was heated in a stainless steel vessel $(V=4 \mathrm{~L})$ to $90{ }^{\circ} \mathrm{C}$ in a water bath. This temperature was held for $10 \mathrm{~min}$ to ensure sufficient whey protein denaturation. The base milk was then cooled in ice water and split in $1.0 \mathrm{~kg}$ aliquots into three stainless steel vessels $(V=1.4 \mathrm{~L})$.

\subsection{Lactose hydrolysis}

For lactose hydrolysis before fermentation, one of the vessels was equilibrated to $38^{\circ} \mathrm{C}$ in a water bath, and 7500 neutral lactase units (NLU). $\mathrm{kg}^{-1}$ Maxilact L2000 (DSM Food Specialties France SAS, Seclin Cedex, France) was added. Hydrolysis was carried out under continuous stirring with a propeller mixer at $200 \mathrm{rpm}$ at $38^{\circ} \mathrm{C}$ for $120 \mathrm{~min}$ to achieve a final lactose content of $<1 \mathrm{~g} / \mathrm{L}$. Usually, fermentation followed immediately afterwards. In the co-hydrolysed approach, lactose hydrolysis was performed during fermentation and at fermentation temperature with a reduced amount of enzyme (3750 NLU. $\mathrm{kg}^{-1}$ ). For that, the milk was stirred only the first $15 \mathrm{~min}$ after simultaneous addition of starter culture and enzyme at $200 \mathrm{rpm}$. 


\subsection{Fermentation}

Fermentation of the reference, the hydrolysed and the co-hydrolysed product was carried out simultaneously at the respective fermentation temperature in the same water bath. Five thermophilic yoghurt starters (mixtures of Streptococcus thermophilus and Lactobacillus delbrueckii ssp. bulgaricus, encoded A-C and E or only S. thermophilus starter, code D), which are still under development and not yet commercially available, were used. During fermentation at $38{ }^{\circ} \mathrm{C}$ for yoghurt or at $42{ }^{\circ} \mathrm{C}$ for Greek-style yoghurt, the $\mathrm{pH}$ of each product was continuously logged to a computer. In case of yoghurt, two independent trials were performed for each condition (hydrolysis $\times$ starter); for Greek-style yoghurt, only starters A and B were used.

At $\mathrm{pH} 4.60 \pm 0.05$ (yoghurt) or at $4.65 \pm 0.05$ (Greek-style yoghurt), the vessels were placed in ice water to stop fermentation. At approx. $23^{\circ} \mathrm{C}$, the gels were broken by moving a perforated plate $(d=78.5 \mathrm{~mm}$, number of holes: 8 , hole diameter $=14 \mathrm{~mm})$ ten times up and down within $30 \mathrm{~s}$. This regime was repeated twice with rests of $4.5 \mathrm{~min}$ in between. Finally, the gel was stirred with a propeller mixer at $400 \mathrm{rpm}$ for $3 \mathrm{~min}$, filled into aseptic polypropylene cups and stored at $4{ }^{\circ} \mathrm{C}$. Greek-style yoghurt was stirred for $2 \mathrm{~min}$ at $400 \mathrm{rpm}$ and another $2.5 \mathrm{~min}$ at $700 \mathrm{rpm}$ to result in a comparably homogeneous stirred product.

\subsection{Forced syneresis}

Syneresis of set (1 day after production) and stirred gels (3 days after production) was determined in quadruplicate by centrifugation $\left(6{ }^{\circ} \mathrm{C}, 1000 \times g, 20 \mathrm{~min}\right)$. The expelled whey was removed by a Pasteur pipette, and syneresis was calculated as the ratio of the mass of expelled whey to total gel mass before centrifugation (Jaros et al. 2002).

\subsection{Rheological analysis}

\subsubsection{Hysteresis loop experiments}

Stirred yoghurt samples stored for 3 and 21 days were equilibrated to $15^{\circ} \mathrm{C}$ and subjected to hysteresis loop experiments in duplicate using the ARES RFS3 with a parallel plate geometry $(d=25 \mathrm{~mm}$, gap $=1.3 \mathrm{~mm})$. After sample loading and resting for $90 \mathrm{~s}$, shear rate was increased linearly from 0 to $100 \mathrm{~s}^{-1}$ within $100 \mathrm{~s}$ and decreased again to $0 \mathrm{~s}^{-1}$ within another $100 \mathrm{~s}$, and shear stress was recorded. For evaluation of the shear stability of the products, the hysteresis loop area was related to the respective maximum shear stress at a shear rate of $100 \mathrm{~s}^{-1}$.

\subsubsection{Viscosity measurements}

Flow properties of stirred gels were analysed after 3- and 21-day storage in the cylinder geometry $\left(d_{i}=32 \mathrm{~mm}, d_{\mathrm{a}}=34 \mathrm{~mm}, h=33.5 \mathrm{~mm}\right)$ of the ARES RFS3 at $15^{\circ} \mathrm{C}$. Samples were loaded and allowed to relax for $300 \mathrm{~s}$. Shear rate was increased from 0.03 to $100 \mathrm{~s}^{-1}$, and five data points per decade were recorded after $100 \mathrm{~s}$ pre-shearing and $10 \mathrm{~s}$ measuring for each point. For better comparison of the samples, yield stress $\tau_{0}$ obtained from fitting to the Herschel-Bulkley model in a shear rate range of $0.03-4 \mathrm{~s}^{-1}$ and apparent viscosity $\eta_{\mathrm{A}}$ at a shear rate of $75 \mathrm{~s}^{-1}$ were used. 


\subsection{Isolation and quantification of EPS}

Five-gram milk gel was weighed into a $50-\mathrm{mL}$ centrifuge tube and neutralised with 1 mol. $\mathrm{L}^{-1} \mathrm{NaOH}$. The samples were then incubated with $250 \mu \mathrm{L}$ Pronase E solution (4.8 g. $\mathrm{L}^{-1}$; Sigma-Aldrich Chemie GmbH, Steinheim, Germany) at $37^{\circ} \mathrm{C}$ overnight for protein digestion (Mende et al. 2012b). To prevent microbial growth, $150 \mu \mathrm{L}$ sodium azide (40 g. $\left.\mathrm{L}^{-1}\right)$ was added. For precipitation of residual protein and cells, $0.7 \mathrm{~mL}$ trichloroacidic acid (TCA; 800 g. $\mathrm{L}^{-1}$ ) was added. Subsequently, samples were heated at $90{ }^{\circ} \mathrm{C}$ for $10 \mathrm{~min}$, cooled for $20 \mathrm{~min}$ in ice water and centrifuged $\left(4{ }^{\circ} \mathrm{C}, 19,000 \mathrm{~g}\right.$, $20 \mathrm{~min}$ ). The supernatant was collected, and the pellet was re-suspended in $0.5 \mathrm{~mL}$ TCA (100 g. $\left.\mathrm{L}^{-1}\right)$ and centrifuged again. The pellet was then discarded, and the supernatants were combined and treated with $16 \mathrm{~mL}$ acetone overnight at $4{ }^{\circ} \mathrm{C}$ to precipitate the polysaccharides. The EPS-containing precipitate was obtained by centrifugation (conditions as above), re-suspended in $5 \mathrm{~mL}$ deionised water and dialysed (molecular mass cut-off 8-10 kDa; Carl Roth GmbH \& Co KG, Karlsruhe, Germany) for $48 \mathrm{~h}$ against deionised water that was changed twice a day. The samples were then freeze-dried (Alpha 1-2, Martin Christ Gefriertrocknungsanlagen GmbH, Osterode, Germany).

The carbohydrate amount was determined photometrically by the phenol-sulphuric acid method (Dubois et al. 1956). Two hundred-microliters appropriately diluted aqueous solution of freeze-dried EPS powder was treated with $200 \mu \mathrm{L}$ phenol solution $\left(50\right.$ g. $\left.\mathrm{L}^{-1}\right)$ and $1 \mathrm{~mL} 98 \%$ sulphuric acid. After $300 \mathrm{~min}$ incubation at $30{ }^{\circ} \mathrm{C}$, absorption was measured at $490 \mathrm{~nm}$ with a He $\lambda$ ios Beta UV-vis Spectrometer (Thermo Scientific Inc., Waltham, USA). The carbohydrate amount was calculated using a calibration function, established with glucose in defined concentrations and expressed as glucose equivalents (mg GE. $\mathrm{kg}^{-1}$ ).

\subsection{Statistics}

Analysis of variance (ANOVA) and subsequent post hoc tests were performed using the SAS Learning Edition 4.1 software (SAS Institute Inc., Cary, NC, USA). Any significances addressed below refer to $P<0.05$.

\section{Results and discussion}

\subsection{Fermentation time}

Incubation time to achieve $\mathrm{pH} 4.60$ (yoghurt) or 4.65 (Greek-style yoghurt) generally ranged from 260 to $640 \mathrm{~min}$. Starters A, B and E needed less and starters C and D more than 480 min (Fig. 1). With the exception of starter D, lowest fermentation time was always obtained for the co-hydrolysed approach where lactose hydrolysis and fermentation took place simultaneously, resulting in the availability of both glucose and lactose for the starter microorganisms.

In yoghurt products made with starters $\mathrm{A}, \mathrm{B}$ and $\mathrm{E}$, also complete hydrolysis of lactose before inoculation accelerated fermentation compared with the respective references. For a specific combination of $S$. thermophilus and L. delbrueckii spp. 


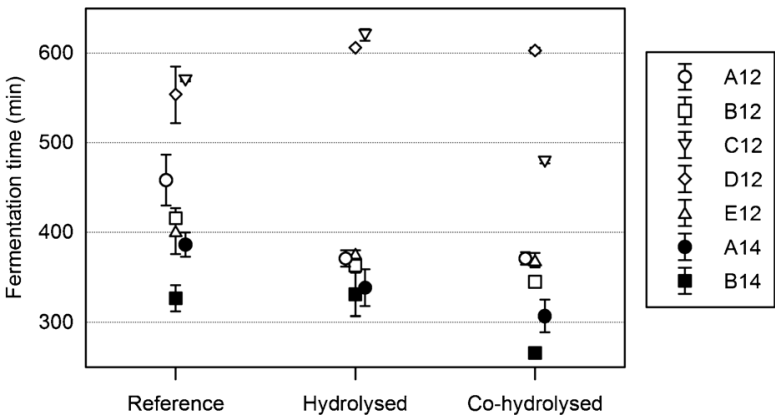

Fig. 1 Fermentation time of regular yoghurt (12) and Greek-style yoghurt (14) produced with starter cultures A-E from differently treated base milks (reference, hydrolysed, co-hydrolysed). Fermentation temperature: regular yoghurt, $38^{\circ} \mathrm{C}$; Greek-style yoghurt, $42{ }^{\circ} \mathrm{C}$.

bulgaricus, shorter fermentation times of hydrolysed milk were also reported by Nagaraj et al. (2009) and O’Leary and Woychik (1976). Matijevíc et al. (2011) found for L. acidophilus La-5 that lactose hydrolysis reduced fermentation time of whey by $2 \mathrm{~h}$, but activity of Bifidobacterium animalis ssp. lactis BB-12 was not promoted. Only starter D exhibited a shorter fermentation time in the reference sample compared to the respective hydrolysed and co-hydrolysed products. The longest fermentation time was observed for starter $\mathrm{C}$ in hydrolysed milk. These observations clearly point on straindependent differences in the preferred carbon sources (Thomas and Crow 1983).

Shorter fermentation times of starters A and B in the protein-enriched substrate can be ascribed to several factors: compared to the $120 \mathrm{~g} \cdot \mathrm{kg}^{-1}$ dry matter substrate, starter dosage was doubled because of the higher protein content, fermentation temperature was $42{ }^{\circ} \mathrm{C}$ instead of $38^{\circ} \mathrm{C}$, and fermentation was stopped at a pH of 4.65; the effects of milk hydrolysis in protein-enriched milk on starters A and B (Greek-style yoghurt) were however similar to those in products with $120 \mathrm{~g} \cdot \mathrm{kg}^{-1}$ dry matter.

\subsection{Flow properties of stirred milk gels}

After 3-day storage of yoghurt A12-E12, the yield stress $\tau_{0}$, which represents the stress below a material resists to flow, depended on the starter, but no significant differences between the reference and the respective (co-)hydrolysed products were observed. During storage for 21 days, $\tau_{0}$ increased significantly (increase of 19-64\%) for all yoghurt samples (Fig. 2). In case of starter E, a much lower $\tau_{0}$ was observed for all products after both 3 and 21 days of storage with an average $\tau_{0}$ of 1.05 and $1.50 \mathrm{~Pa}$, respectively. However, differences in $\tau_{0}$ attributable to milk hydrolysis were generally below $\pm 10 \%$.

The between-starter differences in apparent viscosity $\eta_{\mathrm{A}}$ at a shear rate of $75 \mathrm{~s}^{-1}$, which is related to viscosity perceived during consumption (Shama et al. 1973), were more pronounced, whereas storage-induced viscosity increase was negligible. Reference yoghurt made with starters A or E exhibited a significantly higher $\eta_{\mathrm{A}}$ than the corresponding yoghurt from hydrolysed and co-hydrolysed milk. For yoghurt fermented with starters B, C or D and independent of product storage, relative differences attributable to milk hydrolysis were below $\pm 10 \%$. According to Lucey (2004), prolonged fermentation supports the network formation because of slower 

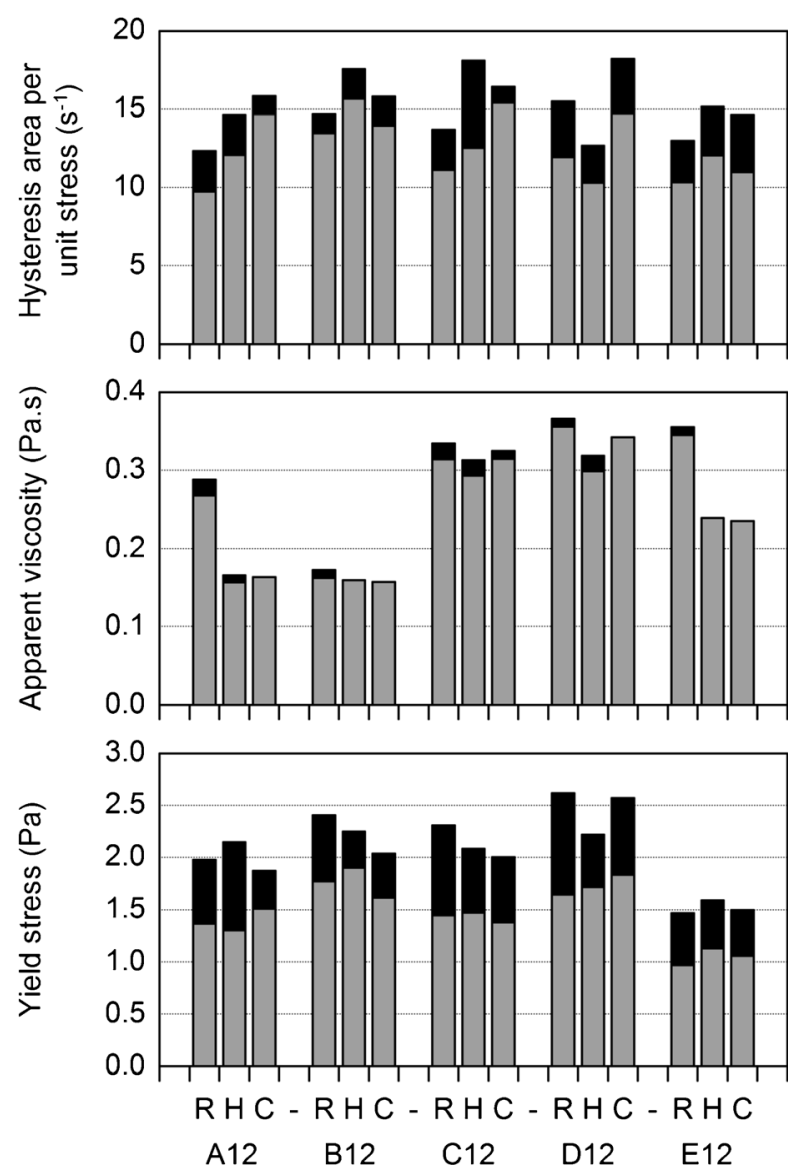

Fig. 2 Yield stress, apparent viscosity and hysteresis area per unit stress of regular yoghurt (12) produced with starters A-E after 3 days (grey) and 21 days (black) of storage $(n=4)$ from differently treated base milks. $R$ reference, $H$ hydrolysed, $C$ co-hydrolysed

casein aggregation, resulting in higher product viscosity. Longer fermentation times in experiments with starters C and D (see Fig. 1) could therefore be the cause for a higher viscosity, independent from lactose hydrolysis. However, the correlation between fermentation time and viscosity is still discussed controversially; a longer incubation time was also found to result in the formation of a gel with lower viscosity (Peng et al. 2009).

Greek-style yoghurt showed significantly higher $\tau_{0}$ and $\eta_{\mathrm{A}}$ compared with regular yoghurt fermented with the same starters. This is mainly because of the protein enrichment and, in our case, particularly because of the higher casein content which allows a higher number of structure-relevant bonds in the milk gels (Lucey 2004). It is evident from Table 1 that the reference products showed always higher $\tau_{0}$ and $\eta_{\mathrm{A}}$ compared with the respective lactose-free products, independent of product storage; these differences were not observed for regular yoghurt (see Fig. 2). The higher fermentation temperature of $42{ }^{\circ} \mathrm{C}$ (instead of $38^{\circ} \mathrm{C}$ ) resulted in lower fermentation times (see Fig. 1). 
Table 1 Yield stress, apparent viscosity and structure degradation of Greek-style yoghurt as affected by starter culture and product storage

\begin{tabular}{|c|c|c|c|c|c|c|}
\hline & \multicolumn{2}{|c|}{ Yield stress $(\mathrm{Pa})$} & \multicolumn{2}{|c|}{ Apparent viscosity (Pa.s) } & \multicolumn{2}{|c|}{$\begin{array}{l}\text { Hysteresis area per unit } \\
\text { stress }\left(\mathrm{s}^{-1}\right)\end{array}$} \\
\hline & 3 days & 21 days & 3 days & 21 days & 3 days & 21 days \\
\hline \multicolumn{7}{|l|}{ Starter culture A } \\
\hline Reference & $6.22 \pm 0.44$ & $9.73 \pm 0.42$ & $0.524 \pm 0.025$ & $0.603 \pm 0.011$ & $15.26 \pm 1.09$ & $18.74 \pm 0.71$ \\
\hline Hydrolysed & $5.12 \pm 0.94$ & $6.48 \pm 1.12$ & $0.472 \pm 0.042$ & $0.466 \pm 0.038$ & $13.93 \pm 0.50$ & $19.03 \pm 0.61$ \\
\hline Co-hydrolysed & $4.61 \pm 0.32$ & $7.09 \pm 1.31$ & $0.455 \pm 0.022$ & $0.509 \pm 0.047$ & $14.12 \pm 1.34$ & $19.74 \pm 0.35$ \\
\hline \multicolumn{7}{|l|}{ Starter culture B } \\
\hline Reference & $7.21 \pm 0.36$ & $11.08 \pm 0.69$ & $0.579 \pm 0.021$ & $0.657 \pm 0.025$ & $13.64 \pm 0.51$ & $16.03 \pm 0.96$ \\
\hline Hydrolysed & $5.81 \pm 0.42$ & $10.12 \pm 0.52$ & $0.487 \pm 0.050$ & $0.578 \pm 0.048$ & $14.20 \pm 1.39$ & $17.87 \pm 1.31$ \\
\hline Co-hydrolysed & $5.26 \pm 0.73$ & $8.29 \pm 0.88$ & $0.457 \pm 0.010$ & $0.543 \pm 0.014$ & $13.45 \pm 2.12$ & $15.73 \pm 0.84$ \\
\hline
\end{tabular}

\subsection{Shear stability of stirred milk gels}

The size of the area enclosed between the upward and downward curves from hysteresis loop experiments can be considered as being proportional to structural breakdown (Folkenberg et al. 2006; Hassan et al. 2003). Figure 3 exemplary shows the response curves of the three stirred yoghurt products made with starter A which enclosed hysteresis areas of nearly the same size. Maximum shear stress $\tau_{\max }$ at $100 \mathrm{~s}^{-1}$ was $42 \mathrm{~Pa}$ for the reference and 28 and $20 \mathrm{~Pa}$ for yoghurt made from hydrolysed milk and by co-hydrolysis, respectively. Consequently, hysteresis area related to $\tau_{\max }$, which has been proposed as a measure for the "degree of structural breakdown" (Jaros et al. 2007), is lower for the reference, indicating higher shear stability.

After 3 days, the reference yoghurt made by starter A was significantly more shear stable than the respective lactose-free products (see Fig. 2). There is a general trend that yoghurt from hydrolysed milk shows a higher or similar susceptibility to shear-induced structure breakdown. The storage-induced increase in the susceptibility to shearinduced structure breakdown ranges from approx. 10 to $30 \%$. The same is true for Greek-style yoghurt (Table 1).

\subsection{Forced syneresis of set and stirred milk gels}

The amount of serum that is expelled from a gel during centrifugation can be considered as a measure of its water-holding capacity (Lucey 2004). Independent of starter culture and milk treatment, forced syneresis of stirred yoghurt ranged from 46.2 to $54.1 \%$, and the corresponding grand average was $49.8 \pm 1.9 \%(n=30)$. Syneresis of stirred Greek-style yoghurt ranged from 32.0 to $35.8 \%$, and the corresponding grand average was $33.8 \pm 1.2 \%(n=12)$. Regarding set gels, forced syneresis was not influenced by lactose hydrolysis, whereas significant differences between the starter cultures were observed. Average values were $37.8 \pm 4.2 \%$ (starter A), $38.3 \pm 2.1 \%$ (starter B), $21.0 \pm 1.6 \%$ (starter C), $22.3 \pm 1.2 \%$ (starter D) and $25.3 \pm 2.2 \%$ (starter E). The amount of whey that was expelled from set Greek-style yoghurt was approx. $5 \%$. 


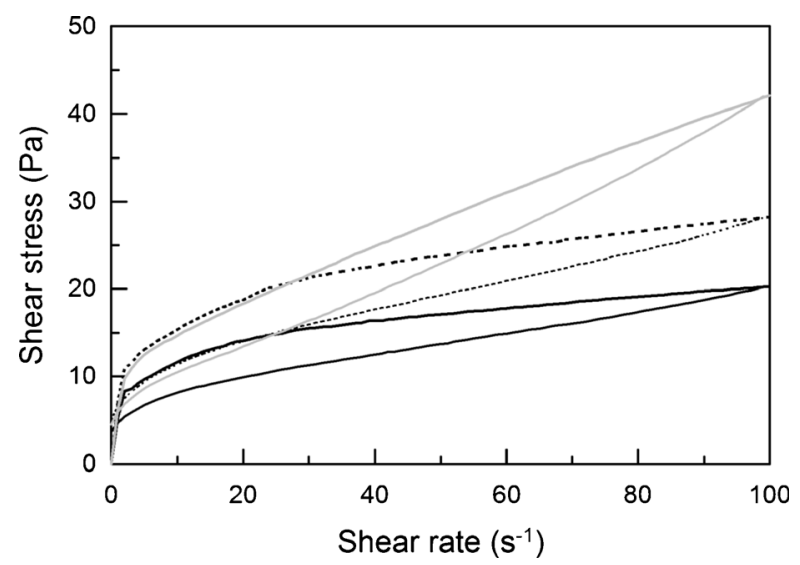

Fig. 3 Hysteresis loops (means of $n=3$ ) of regular yoghurt with starter A after 3-day storage from differently treated base milks. Reference (grey line), hydrolysed (dotted black line) and co-hydrolysed (full black line)

\subsection{Synthesis of EPS}

Amounts of EPS synthesised in the milk gels were significantly influenced by starter culture and, partly, by the milk treatment. Independent of differences in dry matter, EPS concentrations produced from starters A and B were highest (150-250 mg GE.kg ${ }^{-1}$ ), whereas starters C, D and E synthesised amounts between 100 and $150 \mathrm{mg} \mathrm{GE} . \mathrm{kg}^{-1}$ (Fig. 4). It is obvious that hydrolysis of lactose significantly affected EPS synthesis. For some strains, EPS production was more enhanced in yoghurt made from hydrolysed milk and in co-hydrolysis (e.g. B12, E12, A14 and minor differences for D12), whereas in products $\mathrm{A} 12$ and $\mathrm{B} 14$, only hydrolysis of the milk before fermentation enhanced EPS synthesis. An exception was the co-hydrolysed product C12 with a higher EPS concentration compared to the reference and the product from hydrolysed milk.

It is well known that substrate composition, especially the carbohydrate source among other factors (nitrogen source and $\mathrm{C} / \mathrm{N}$ ratio, fermentation conditions, e.g. $\mathrm{pH}$, temperature), affects the amount of EPS synthesised during fermentation (Cerning 1995). Some authors

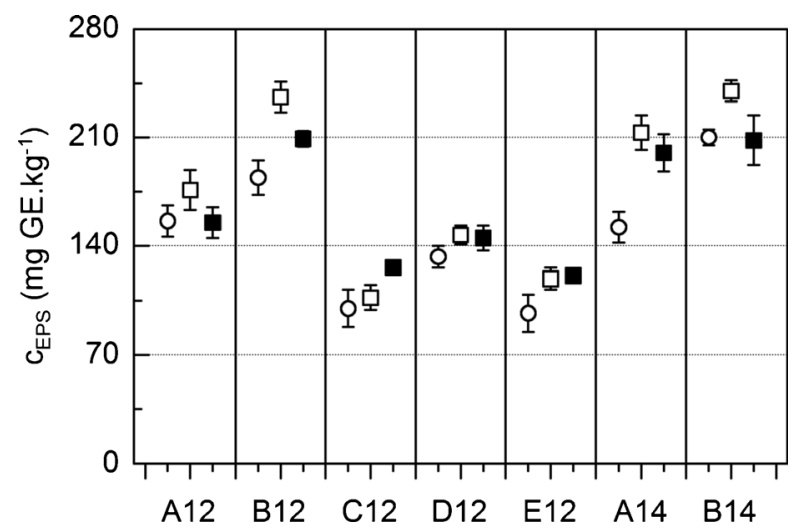

Fig. 4 Exopolysaccharide concentrations in regular yoghurt made with starters A-E (A12-E12) and in Greek-style yoghurt (A14, B14) from differently treated base milks. Circles, reference; open squares, hydrolysed; closed squares, co-hydrolysed 
reported a strain specific effect of the carbohydrate source on EPS synthesis. Whereas, e.g. L. delbrueckii ssp. bulgaricus DSM 20081 synthesised more EPS in lactose media (Mende et al. 2012a), Petry et al. (2000) achieved higher EPS concentrations for strains CNRZ 1187 and CNRZ 416 by using glucose. Recently, this strain-specific relation between EPS production and carbohydrate source was also shown for different $S$. thermophilus strains (Mende et al. 2012b). Consequently, results from Fig. 4 lead to the conclusion that the starters used in this study have different preferences for the carbohydrate source. Starter C seems to prefer the simultaneous presence of glucose and lactose (achieved during cohydrolysis), whereas starters A and B produced more EPS with glucose as the only carbon source (achieved by complete lactose hydrolysis before inoculation). For starters D and E, the presence of glucose seemed to result in higher EPS concentrations, but it made no difference whether lactose was also still present.

When considering the rheological properties of the different products (Fig. 2), it is obvious that the amount of synthesised EPS does not correlate with viscosity. Starters A and B produced the highest EPS concentrations but exhibited significantly lower $\eta_{\mathrm{A}}$ than yoghurt produced by starters C, D and E. EPS are known to generally affect water binding capacity and increase viscosity of fermented milks (Folkenberg et al. 2005; Mende et al. 2013). Mende et al. (2013) demonstrated that, for the same type of EPS, an increase of its concentration results in an increase of apparent viscosity in milk gels. The fact that EPS concentration and $\eta_{\mathrm{A}}$ do not correlate in the present study confirms the importance of the differences in the macromolecular properties of EPS (such as molecular mass, branching, charge or ropiness) from different starters on the viscosity of yoghurt (e.g. Duboc and Mollet 2001; Ruas-Madiedo et al. 2002). Furthermore, it is unknown whether different kinds of EPS were synthesised, which may additionally interact with each other in a positive or negative way.

\subsection{Effect of fermentation temperature}

Flow properties of yoghurt B12 at $38{ }^{\circ} \mathrm{C}$ were only marginally affected by lactose hydrolysis (see Fig. 2), whereas both $\tau_{0}$ and $\eta_{\mathrm{A}}$ were significantly higher for the reference product in case of Greek-style yoghurt produced at $42{ }^{\circ} \mathrm{C}$ (see Table 1). To evaluate the impact of the different temperature, additional fermentations for Greekstyle yoghurt with starter B were carried out at $38{ }^{\circ} \mathrm{C}$ (B14_38).

Lower temperature $\left(38^{\circ} \mathrm{C}\right.$ ) resulted in prolonged fermentation time (60 min longer). But, after 3 days of storage, no significant differences of $\eta_{\mathrm{A}}$ of the stirred gels were found between lactose-containing and lactose-free milk gels (Fig. 5). Compared to fermentation at $42{ }^{\circ} \mathrm{C}$, the products exhibited lower $\eta_{\mathrm{A}}$, which is in line with findings from Haque et al. (2001) who obtained also higher viscosity at higher fermentation temperature. During storage (between 3 and 21 days), more structure was rebuilt in the reference product, resulting in an increase in viscosity of $22 \%$ compared to the hydrolysed (17\%) and the co-hydrolysed product (12\%).

There is a trend that during fermentation at $38{ }^{\circ} \mathrm{C}$, more EPS (approx. $250 \mathrm{mg}$ GE. $\mathrm{kg}^{-1}$ ) were synthesised compared to fermentation at $42{ }^{\circ} \mathrm{C}$ (approx. $220 \mathrm{mg}$ GE. $\mathrm{kg}^{-1}$ ). Together with the longer fermentation time at $38^{\circ} \mathrm{C}$, this implies that EPS synthesis of starter B is growth associated. Various studies found that EPS synthesis of many bacterial strains is growth-associated (e.g. De Vuyst et al. 1998; Petry et al. 2000; Welman and Maddox 2003). Mende et al. (2012a) observed a significant increase of the 


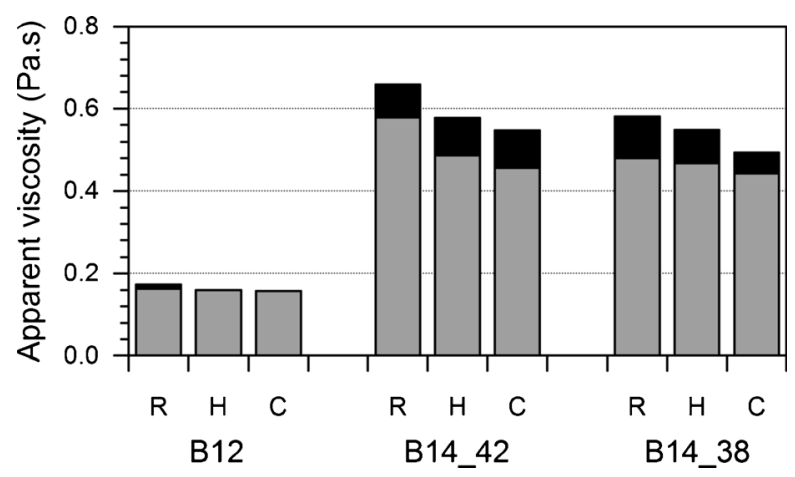

Fig. 5 Means of apparent viscosity of regular yoghurt (12) and Greek-style yoghurt (14) made with starter B after 3 days (grey) and 21 days (black) of storage $(n=4)$ from differently treated base milks. $R$ reference, $H$ hydrolysed, $C$ co-hydrolysed. Numbers 38 and 42 denote fermentation temperature

colony count for L. delbrueckii ssp. bulgaricus DSM 20081 and associated higher EPS concentration when fermentation temperature was decreased from 45 to $37^{\circ} \mathrm{C}$.

The presence of more EPS in Greek-style yoghurt fermented at $38{ }^{\circ} \mathrm{C}$ could cause the slower structure rebuilding of the stirred products, so that significant differences in apparent viscosity between products fermented at $38{ }^{\circ} \mathrm{C}$ were only detectable after more than 3-day storage. During stirring of set milk gels, the protein network is broken into smaller aggregates, resulting in a reduction of viscosity, which is then partially reestablished during storage. This regeneration of the network was found to be hindered by the presence of EPS (Girard and Schaffer-Lequart 2007; Kristo et al. 2011). Girard and Schaffer-Lequart (2007) added defined amounts of EPS to milk, prepared gels by acidification with glucono- $\delta$-lactone and discovered a decrease of regeneration capacity of the gels with the increase of EPS concentration.

\section{Conclusions}

In the present study, the influence of lactose hydrolysis (before or during fermentation) on the rheological properties of fermented milk products was investigated by using five starter cultures and two product types (yoghurt and Greek-style yoghurt). Within each trial (reference, pre-hydrolysed substrate, co-hydrolysed approach), fermentations were carried out simultaneously with the same starter culture. Results show that the influence of lactose hydrolysis on the properties of the fermented dairy products strongly depends on starter culture and substrate. Apparent viscosity of fermented milks from starter cultures C and D was only marginally affected by hydrolysis of lactose (relative differences always below $10 \%$ ), whereas products from starters $\mathrm{A}$ and $\mathrm{E}$ exhibited significant lower viscosity (decrease of 45 and $32 \%$, respectively) compared with their respective references. For starter B, it became evident that yield stress and apparent viscosity of Greek-style yoghurt decreased because of lactose hydrolysis, whereas regular yoghurt was not affected. Determination of EPS concentration showed a trend to more EPS synthesised in hydrolysed milk compared with the reference substrate. For a better understanding of the impact of the EPS on the rheological properties of the products, further studies are needed to determine the strainspecific EPS characteristics. 
Acknowledgments We would like to thank DSM Food Specialties for kindly providing the starter cultures for this study.

\section{References}

Adhikari K, Dooley LM, Chambers E, Bhumiratana N (2010) Sensory characteristics of commercial lactosefree milks manufactured in the United States. LWT-Food Sci Technol 43:113-118

Cerning J (1995) Production of exopolysaccharides by lactic acid bacteria and dairy propionibacteria. Lait 75 : $463-472$

De Vuyst L, Vanderveken F, De Ven SV, Degeest B (1998) Production by and isolation of exopolysaccharides from Streptococcus thermophilus grown in a milk medium and evidence for their growth-associated biosynthesis. J Appl Microbiol 84:1059-1068

Duboc P, Mollet B (2001) Applications of exopolysaccharides in the dairy industry. Int Dairy J 11:759-768

Dubois M, Gilles KA, Hamilton JK, Rebers PA, Smith F (1956) Colorimetric method for determination of sugars and related substances. Anal Chem 28:350-356

Folkenberg DM, Dejmek P, Skriver A, Ipsen R (2005) Relation between sensory texture properties and exopolysaccharide distribution in set and in stirred yoghurts produced with different starter cultures. J Texture Stud 36:174-189

Folkenberg DM, Dejmek P, Skriver A, Guldager HS, Ipsen R (2006) Sensory and rheological screening of exopolysaccharide producing strains of bacterial yoghurt cultures. Int Dairy J 16:111-118

Girard M, Schaffer-Lequart C (2007) Gelation of skim milk containing anionic exopolysaccharides and recovery of texture after shearing. Food Hydrocoll 21:1031-1040

Günther E (1983) Verfahren zur herstellung von joghurt mit reduziertem Lactosegehalt. Patent DE 3146198 A1

Haque A, Richardson RK, Morris ER (2001) Effect of fermentation temperature on the rheology of set and stirred yogurt. Food Hydrocoll 15:593-602

Harju M, Kallioinen H, Tossavainen O (2012) Lactose hydrolysis and other conversions in dairy products: technological aspects. Int Dairy J 22:104-109

Hassan AN, Ipsen R, Janzen T, Qvist KB (2003) Microstructure and rheology of yogurt made with cultures differing only in their ability to produce exopolysaccharides. J Dairy Sci 86:1632-1638

Husain Q (2010) Beta galactosidases and their potential applications: a review. Crit Rev Biotechnol 30:41-62

Ibarra A, Acha R, Calleja MT, Chiralt-Boix A, Wittig E (2012) Optimization and shelf life of a low-lactose yogurt with Lactobacillus rhamnosus HN001. J Dairy Sci 95:3536-3548

Jaros D, Heidig C, Rohm H (2007) Enzymatic modification through microbial transglutaminase enhances the viscosity of stirred yogurt. J Texture Stud 38:179-198

Jaros D, Haque A, Kneifel W, Rohm H (2002) Influence of the starter culture on the relationship between dry matter content and physical properties of stirred yogurt. Milchwissenschaft - Milk Sci Int 57:447-450

Jelen P, Tossavainen O (2003) Low lactose and lactose-free milk and dairy products — prospects, technologies and applications. Aust J Dairy Technol 58:161-165

Kristo E, Miao Z, Corredig M (2011) The role of exopolysaccharide produced by Lactococcus lactis subsp. cremoris in structure formation and recovery of acid milk gels. Int Dairy J 21:656-662

Lucey JA (2004) Cultured dairy products: an overview of their gelation and texture properties. Int J Dairy Technol 57:77-84

Martins AR, Manera AP, Monteiro RL, Burkert JFM, Burkert CAV (2012) Simultaneous enzymatic hydrolysis and lactic fermentation to obtain a yogurt with low lactose content. Ciência Agrotecnol 36:551-559

Matijević B, Lisak K, Božanić R, Tratnik L (2011) Impact of enzymatic hydrolyzed lactose on fermentation and growth of probiotic bacteria in whey. Mljekarstvo 61:154-160

Mende S, Krzyzanowski L, Weber J, Jaros D, Rohm H (2012a) Growth and exopolysaccharide yield of Lactobacillus delbrueckii ssp. bulgaricus DSM 20081 in batch and continuous bioreactor experiments at constant pH. J Biosci Bioeng 113:185-191

Mende S, Mentner C, Thomas S, Rohm H, Jaros D (2012b) Exopolysaccharide production by three different strains of Streptococcus thermophilus and its effect on physical properties of acidified milk. Eng Life Sci 12:466-474

Mende S, Peter M, Bartels K, Dong T, Rohm H, Jaros D (2013) Addition of purified exopolysaccharide isolates from $S$. thermophilus to milk and their impact on the rheology of acid gels. Food Hydrocoll 32 : $178-185$ 
Mlichová Z, Rosenberg M (2006) Current trends of $\beta$-galactosidase application in food technology. J Food Nutr Res 45:47-54

Nagaraj M, Sharanagouda B, Manjunath H, Manafi M (2009) Standardization of different levels of lactose hydrolysis in the preparation of lactose hydrolysed yoghurt. Iran J Vet Res 10:132-136

Novalin S, Neuhaus W, Kulbe KD (2005) A new innovative process to produce lactose-reduced skim milk. J Biotechnol 119:212-218

O'Leary VS, Woychik JH (1976) Utilization of lactose, glucose, and galactose by a mixed culture of Streptococcus thermophilus and Lactobacillus bulgaricus in milk treated with lactase enzyme. Appl Environ Microbiol 32:89-94

Peng Y, Horne DS, Lucey JA (2009) Impact of preacidification of milk and fermentation time on the properties of yogurt. J Dairy Sci 92:2977-2990

Petry S, Furlan S, Crepeau MJ, Cerning J, Desmazeaud M (2000) Factors affecting exocellular polysaccharide production by Lactobacillus delbrueckii subsp. bulgaricus grown in a chemically defined medium. Appl Environ Microbiol 66:3427-3431

Ruas-Madiedo P, Hugenholtz J, Zoon P (2002) An overview of the functionality of exopolysaccharides produced by lactic acid bacteria. Int Dairy J 12:163-171

Schaafsma G (2008) Lactose and lactose derivatives as bioactive ingredients in human nutrition. Int Dairy J 18:458-465

Shama F, Parkinson C, Sherman P (1973) Identification of stimuli controlling the sensory evaluation of viscosity I. Non-oral methods. J Texture Stud 4:102-110

Thomas TD, Crow VL (1983) Lactose and sucrose utilization by Streptococcus thermophilus. FEMS Microbiol Lett 17:13-17

Toba T, Arihara K, Adachi S (1986) Quantitative changes in oligosaccharides during fermentation and storage of yogurt inoculated simultaneously with starter culture and $\beta$-galactosidase preparation. J Dairy Sci 69: 1241-1245

Vasiljevic T, Jelen P (2003) Retention of $\beta$-galactosidase activity in crude cellular extracts from Lactobacillus delbrueckii ssp. bulgaricus 11842 upon drying. Int J Dairy Technol 56:111-116

Vénica CI, Bergamini CV, Zalazar CA, Perotti MC (2013) Effect of lactose hydrolysis during manufacture and storage of drinkable yogurt. J Food Nutr Disord 2:5

Welman AD, Maddox IS (2003) Fermentation performance of an exopolysaccharide-producing strain of Lactobacillus delbrueckii subsp. bulgaricus. J Ind Microbiol Biotechnol 30:661-668 